\title{
Exploration on the Application of Blockchain Audit
}

\author{
Chang Cheng \\ School of Accounting \\ Zhongnan University of Economics and Law \\ Wuhan, China 430073 \\ School of Accounting \\ Zhejiang University of Finance and Economics \\ Hangzhou, China 310018
}

\author{
Qunjia Huang \\ School of Accounting \\ Zhejiang University of Finance and Economics \\ Hangzhou, China 310018
}

\begin{abstract}
With the rise of Bitcoin, the blockchain technology as its core technology has received wide attention from all walks of life. Blockchain technology demonstrates its potential for audit applications by virtue of decentralization, transparency, and data tampering. This paper starts from the characteristics of blockchain technology and discusses the application value of blockchain in audit. Through the comparative study on the blockchain audit application of the international "big four" firms and Chinese firms, the impact of blockchain audit on the firm's business and the working methods of auditors is discussed. Based on this, relevant suggestions are put forward for the future development of blockchain audit.
\end{abstract}

Keywords—blockchain; audit; application; accounting firm

\section{INTRODUCTION}

In recent years, with the rapid development of China's economy, the company's financial data has shown explosive growth. As a supplier that provides audit and verification services for the company's financial data, the audit work and audit difficulties faced by accounting firms have been greatly improved. In particular, the incidents of financial fraud of listed companies have increased in the past 10 years, which has greatly damaged the interests of investors, interfered with the normal operation of the market, and also increased the audit risk and audit pressure faced by accounting firms. Accounting firms urgently need to solve the problems of high audit cost, low efficiency and high audit risk.

As various cryptocurrencies emerged on a global scale, blockchain, the core supporting technology for Bitcoin, came into view. Blockchain technology is considered to be a milestone innovation after the Internet, with broad application prospects and application value [1]. Since its birth, blockchain technology has received significant attention from the financial community, government, and academia. Countries are actively exploring blockchain technology. As early as December 2015, NASDAQ of the United States launched Linq, a securities trading platform based on blockchain technology, which pioneered the decentralization of financial securities. In January 2016, the British government issued a special report research of the blockchain, which raised the development of blockchain technology to the national strategic level. In October 2016, China officially released the White Paper on China's
Blockchain Technology and Application Development. This first official guidance document in the field of blockchain demonstrates the country's determination to promote the blockchain technology. [2]

At present, blockchain technology has been maturely applied in the field of Bitcoin transactions, and further extended to applications such as audit, accounting, digital assets, and bills. Blockchain, as the underlying support technology of a database, has the characteristics that data can't be falsified, traceable, highly transparent, safe and reliable, which greatly meets the core requirements of audit work, can effectively reduce the risk of audit work, and reduce the cost of audit work and improve the efficiency of audit work, providing practical and effective solutions for current prevailing audit issues. Audit is the mainstream business of accounting firms and the main source of income. How to grasp the development opportunities of the current blockchain audit will play a vital role in the future development of accounting firms.

In the research process of this article, the author noticed that since 2016, the international "big four" accounting firms have set up corresponding blockchain teams, actively exploring the application of blockchain technology in audit and determining a global blockchain layout. At the same time, Chinese domestic capital firms have not made any progress in the exploration of blockchain audit.

Based on this status quo, this paper has certain forwardlooking and application value, which can provide reference for the application of blockchain audit in China's domestic capital. This paper will introduce the relevant theories and advantages of blockchain technology in the first part, and discusses the application advantages and prospects of blockchain technology in audit in the second part. In the third part, this paper makes a comparative study on the application status of blockchain audit of the international "big four" accounting firms and Chinese capital firms, with a view to further exploring the gaps and shortcomings between Chinese firms and the international big four. In the end, this paper will provide relevant suggestions and countermeasures for the application of blockchain audit by Chinese accounting firms. 


\section{OVERVIEW OF BLOCKCHAIN}

\section{A. Definition of Blockchain}

The concept of blockchain was first proposed by Satoshi Nakamoto in 2008 in "Bitcoin: A Peer-to-Peer Electronic Cash System". In this article, Nakamoto has conceived an electronic cryptocurrency payment method based on Bitcoin, and the blockchain is the core technology to support this payment method [3]. In early 2009, Satoshi Nakamoto dug up the first block of Bitcoin on a small server in Helsinki, Finland. This is the first time the blockchain has moved from theory to practice. Subsequently, more and more blocks were developed, and the blocks were interconnected by network technology to form an independent system, namely, the blockchain [4]. Although the public's enthusiasm for Bitcoin has cooled, blockchain, as its underlying technology, is increasingly promising.

Currently, there is no clear definition of blockchain in academia. In a narrow sense, blockchain is a kind of data that connects encrypted data (blocks) in a chain according to the time sequence. Such data is decentralized (transactions do not require the participation and confirmation of a third party), cannot be tampered with or forged, can be stored safely, and can be verified by broadcasting in the system [5]. In a broad sense, blockchain is a new database technology: using encrypted chain block data structure to verify and store data, using distributed node consensus algorithm to generate and update data, using cryptography to ensure data transmission and access security, and using smart contracts to program and manipulate data [6]. The blockchain and blockchain techniques discussed in this paper refer to the generalized blockchain.

\section{B. Characteristics of Blockchain}

\section{1) Distributed system}

Different from the centralized data management system, the verification, accounting, storage and maintenance of blockchain data are based on the distributed system structure [7]. In the database system constructed by blockchain technology, each node in the system (such as a company or an individual) has a account book. Any new transaction that occurs in the system must be broadcast system-wide. After verification by all nodes, the information of this transaction can be recorded and stored. Otherwise, it is invalid information and will not be recorded. After the transaction information of any node is verified, it is also copied and stored by all other nodes while being stored by the current node. That is to say, the account in the hands of each node is a complete account book, recording all complete transaction information that has occurred in the system. The data $o$ account book for each node is consistent and unique.

\section{2) Decentralization}

Different from the centralization of traditional databases, all transaction verification requires a central recognition. The blockchain database does not have a central organization. The status of each node is equal. All transaction verification requires each node's recognition of the systems. All transaction data is stored in each node of the system, achieving a point-to-point decentralized network [8].

\section{3) Time series data}

The blockchain stores data through a time-stamped chain structure [9]. All data is sorted in chronological order, and once the data is recorded, it cannot be changed and will be saved permanently. At each node, data can be added, but cannot be modified and deleted.

\section{4) Asymmetric encryption}

Blockchain technology encrypts data by asymmetric encryption [10]. Asymmetric encryption requires two keys: a public key (public key) and a private key (private key), which are used to encrypt data and decrypt data, respectively. In a blockchain system, when one party sends a message to the other party, a pair of public and private keys is generated. The public key is public, but the private key is not public. Only the party receiving the information has a private key, which can decrypt the data. Anyone who only knows the public key information can't decrypt the data. This is asymmetric encryption. The technical feature of asymmetric encryption can greatly increase the security of data transmission within the database.

\section{Advantages of Blockchain}

\section{1) Security}

The verification, storage, and transmission of all transactions in a traditional centralized system require the participation of a central server. Once the central server is attacked maliciously, the entire system is paralyzed and the system stability is low. And all the information is recorded in the central server. Once hacked, the risk of data being maliciously tampered with is greater. However, due to the decentralized distributed structure of the blockchain system, even if a single node is attacked, other nodes can still work as usual, and the system stability is high. Even if the data of a single node is tampered with later, other nodes in the whole network fail to verify the transaction, and the data will not be written into the account book of any node, which makes the data untamperable. Coupled with the unique asymmetric encryption of the blockchain, the data security within the blockchain system has been greatly improved. Unless someone can manipulate more than $51 \%$ of the nodes in the system, no change can be made to the data in the database. However, due to the huge computing power required, it is extremely unlikely to happen [11]. At the same time, the possibility of incorrect financial data in the system will be greatly reduced. The data entered by mistake will not be approved by other nodes. This largely guarantees the accuracy of the data.

\section{2) Real-time update}

Whenever any activity occurs in any node of the blockchain system, the system will notify other nodes through the whole network broadcast. After verification, the economic activity data will not only be stored in the account book of current node, but also automatically copied and stored in the account books of other nodes. This networkwide update of the data is real-time. With this feature, it can also achieve comprehensive supervision. In other words, all 
user of the whole network carry on the timely supervision to the economic activity, avoiding the problem.

\section{3) Data traceability}

The data in the blockchain is integrated into a chain structure in chronological order. Each blockchain has a timestamp that records the time information generated by the blockchain. And time is irreversible. Such time series data cannot be deleted and modified once it is generated. This feature greatly guarantees the traceability of data. Each node on the blockchain system has all the data since the system was created, which is convenient for managers and supervisors to trace the entire network data according to the timestamp at any node.

\section{4) Data is transparent}

The blockchain is a highly open system. All data in the blockchain is open to everyone. In addition to the invisible private information of both parties to the transaction, everyone can query the entire network data in the blockchain database through a public port [12]. Therefore, blockchain data is highly transparent and open.

\section{Summary}

Blockchain technology has the technical features of distributed systems, decentralization, time series data, and asymmetric encryption. With the support of these technical features, the blockchain can build a highly transparent database that can store data securely, update data in real time, information cannot be tampered with, and data can be traced, and can be fully shared. Compared with the traditional database, the blockchain database can ensure the accuracy, authenticity and timeliness of the data.

\section{The AdVANTAges OF BlockChaIn BeING APPliED TO THE AUDIT INDUSTRY}

Audit is a monitoring activity for economic business. The essence of the audit is that an independent third party will review and supervise the authenticity, accuracy and compliance of the economic activities of the audited entity, and feedback the results.

\section{A. Reducing Audit Costs}

At present, the main audit work in China is still completed through traditional on-site audit. As it known to all, the labor cost and time cost of on-site audit are very huge. In terms of time cost, taking the annual report audit of the company as an example, it can vary from one week to two or three months depending on the size of the company and the complexity of the economic business. In terms of labor costs, the traditional audit workload is large, and a large number of audit procedures cost the auditors a lot of time and effort. The annual report audit of a general enterprise requires an audit team of at least 3-5 people. In the case of an enterprise initial public offering (IPO) project, an audit team of more than 10 people is required.

At present, the audit cost is mainly on the verification of the authenticity and accuracy of the economic business of the audited enterprise, such as the external confirmations and the evidence. In the case of external confirmations, as a highly reliable audit procedure, auditors usually perform a large number of correspondence procedures for the balance of accounts receivable and accounts payable and the balance of bank deposits to verify the authenticity and accuracy of the data. In the process of confirmations, the letter of confirmation itself will incur a certain fee, and more importantly, the letter of confirmation will take a long time. When using the positive letter of confirmation, the inquiries will not necessarily be proactively replied. At this time, it is necessary to start the second letter of confirmation, and the time spent is further lengthened. Finally, the results of the confirmation were received, but the auditor could not guarantee $100 \%$ reliability of the letter of confirmation due to consideration of whether the letter of confirmation was familiar with or whether the letter of confirmation was taken seriously. However, in the blockchain system, all financial information has been verified by other nodes, and it is verifiable and irreversible, which is very real and accurate. At that time, auditors can fully trust these financial data, reduce many unnecessary audit procedures, and shorten the audit time, greatly reducing the amount of manpower and resources required to obtain the reliability of financial information.

\section{B. Reducing Audit Risk}

The audit risk mentioned is a risk of fraud in many cases. Listed companies may carefully design fraud to cover up losses or inflated gains. Such fraudulent behaviors are usually carefully designed and colluded, not only tampering with financial data, but also forging on original documents. This type of fraud is difficult to find even after experienced auditors have implemented adequate audit procedures, thus exposing auditors to the risk of audit failure and litigation. In addition to the risk of fraud, traditional audit is accompanied by other issues. For example, there are problems of missing data and corruption. Traditional audit usually copies the financial data of the audited entity and imports it into the audit software used for data processing and analysis. In this process, there is a high probability of data loss and corruption. Without comprehensive and complete financial data, the possibility of auditors issuing false audit opinions is increased, and audit risks are correspondingly improved. Another example is the limitations of audit sampling [13]. Taking the vouching as an example, the traditional audit can only check the original vouchers by extracting some vouchers, but cannot achieve full vouching or verify the authenticity of each voucher. Such an audit can only provide reasonable assurance, not an absolute guarantee. The limitations of traditional audit procedures expose auditors to higher audit risks.

In the blockchain system, the above problems can be solved. First of all, for the risk of fraud, any modification of the financial data will be broadcast on the whole network, and all nodes will get the message of data modification. If the nodes of the whole network don't verify, this data cannot be modified. If the relevant regulatory authorities are incorporated into the blockchain network, the regulatory authorities can track all of the company's business trends in 
real time, monitor abnormal behaviors at any time, achieve on-the-spot supervision, and reduce after-the-fact risks. Moreover, not only the regulatory authorities, but all other nodes throughout the network can achieve this kind of supervision function, which effectively restricts the financial fraud behavior of enterprises. At the same time, even if the company really deletes or falsifies the financial data, the blockchain system will leave traces, and the auditors can easily find and track those changes and find out the reasons.

Secondly, the blockchain system is a highly transparent system for data loss and limitations of audit program. As long as the auditors can be authorized to log into one of the public ports, they can query all the finance data of the blockchain system since its inception. And these financial data are permanent, non-tamperable, true and accurate. In this way, the financial data obtained by the auditors is comprehensive and true. This makes it possible to achieve full audit.

\section{Achieving Real-time Audit}

The traditional audit is a review of the economic activities of the audited entity in the past period of time, with a certain lag in time, which gives the enterprise time to tamper with and delete financial data [14]. The transmission of data takes time. Taking the bank statement as an example, there is a transaction recorded by the bank but not recorded by the enterprise, it is difficult for the enterprise to detect this problem and make accounting treatment of this business before the bank statement is sent to the enterprise. This makes the financial data on the company's books inherently lagging, not necessarily accurate.

When the enterprise records and stores all transactions in the blockchain, the information of each node is updated in real time, and the data of the blockchain is self-contained with time information, the auditor can track the blockchain in real time to supervise the company's books, without leaving time for the company to tamper with or delete the data, effectively reducing the risk of financial fraud. At the same time, for the lag of financial information, the data transmission in the blockchain system is almost real-time. The transaction will be broadcast to the remaining nodes at the moment of bank account entry, and the transaction will be automatically updated to the account book of enterprise. All financial data on the corporate books is updated and accurate in real time. These features of the blockchain make it possible to implement real-time audit.

\section{Summary}

Blockchain audit provides a good solution to the problems of traditional audit methods, such as high audit costs, high audit risk, and audit program limitations. Blockchain technology can reduce the audit workload, shorten the audit cycle, and greatly reduce the audit cost; it can also achieve data non-tamperable, real-time update of the whole network, reduce financial fraud and improve the accuracy of corporate accounts. In general, the application of blockchain technology to audit can greatly improve audit quality and reduce audit costs.
In the blockchain era, many basic mechanical audits will be replaced by blockchain applications, which will save the auditor's time and effort. Auditors can put more of their energy into data analysis and decision-making that requires professional judgment. The focus of the financial staff will be transferred to corporate decision-making and value management. This indirectly promotes the improvement of the professional quality and comprehensive ability of financial personnel. In the future, there will be no need for low-level audit talents, but more comprehensive talents with high professionalism and strategic vision.

When enterprises store all their internal economic activities in the blockchain system, the blockchain system itself is highly open and transparent; data is not tamperable, safe and reliable; and there are the characteristics such as time series data, and comprehensive supervision, which enables enterprises to use blockchain-based financial system to fully guarantee the truthfulness, accuracy and compliance of the data. That is to say, enterprises are likely to no longer need external auditors in the future, and their blockchain system can meet the real and reliable requirements of stakeholders for corporate financial data. As a result, the accounting services of this third-party intermediary agency will undergo major changes.

\section{ANALYSIS ON THE STATUS QUO OF BLOCKCHAIN AUDIT}

\section{A. Exploration of Blockchain Audit by Foreign Firms}

Currently, the research on blockchain audit is still in its infancy. However, due to the unique technological advantages of the blockchain, the international "Big Four" accounting firms (Deloitte, Ernst \& Young, PricewaterhouseCoopers, KPMG) began their research from the beginning of the blockchain. Taking Deloitte's accounting firm as an example, Deloitte is the first accounting firm to enter the blockchain field. As early as 2014, Deloitte launched a one-stop blockchain service platform "Rubix" [16], which mainly provides blockchain application services and corresponding consulting services. In May 2016, Deloitte established the first blockchain laboratory in Dublin to research new projects and solutions using blockchain. In January 2017, Deloitte established a second blockchain laboratory in New York. On August 28, 2018, Deloitte and the Monetary Authority of Singapore signed an agreement to cooperate on the application of blockchain technology to connect funds transfer with securities transfer. After Deloitte, Ernst \& Young, KPMG and PricewaterhouseCoopers also established their own blockchain research teams and began their respective blockchain layouts. In 2017, Ernst \& Young launched its own blockchain platform "Ops Chain" to provide enterprise blockchain technology services. As of December 31, 2017, Ernst \& Young has established three blockchain laboratories in the United States, the United Kingdom, and India. In 2006, PricewaterhouseCoopers hired 15 blockchain talents at a high salary and formed the first blockchain research team. In March 2017, PricewaterhouseCoopers partnered with Alibaba to explore a new blockchain technology to solve 
development of audit and consulting projects, and have established a database to realize the global sharing within accounting firms. Moreover, the audit software used by the "Big Four" is also self-developed and has independent intellectual property rights. Deloitte invested in emerging blockchain startups at the end of 2016. The purpose is to use blockchain technology to provide customers with highquality payment and clearing financial services. At present, according to the known situation, China's accounting firms have almost no involvement in blockchain technology.

\section{PROSPECTS AND RECOMMENDATIONS FOR CHINA'S BLOCKCHAIN AUDIT} application of blockchain in accounting is concerned, the first enterprise involved in China is the financial software information service provider Kingdee. In 2017, it began to enter the application of blockchain technology in financial software. At the time when the international "Big Four" accounting firms studied on the blockchain, the "Eight Big" Chinese firms (BDO, Ruihua Certified Public Accountants, Pan-China Certified Public Accountants, Dahua, Grant Thornton International Ltd, Shine Wing, Wuyige Certified Public Accountants LLP and Baker Tilly International), which enjoy a great reputation in the field of audit, finance and taxation in China, have not made any exploration in the field of blockchain.

\section{Deficiency}

In business, the accounting firm's business income is mainly composed of two components: attestation service and non-attestation services. The attestation service is the audit service people usually say. This kind of business is the main source of income for the current firm, especially the Chinese firms. Non-attestation services include management consulting revenue and asset valuation income, tax service income, etc. Such businesses account for a relatively small proportion. However, in today's increasingly fierce competition for attestation service, many firms have gradually turned their attention to non-attestation service, with a view to vigorously develop non-attestation business to enhance competitiveness. Combined with the previous article, the emergence of blockchain technology will most likely change the demand for attestation service in future enterprises, and realize the "self-audit" of enterprises, thus impacting the firm's attestation service. The management consulting business in the non-attestation service has higher requirements for the comprehensive quality and professional quality of the employees, and the work is irreplaceable and less affected by the blockchain. Whether it is a foreigninvested firm or a Chinese-funded firm, the proportion of forensic services income to total income is high, and the proportion of Chinese-funded firms is higher. Such a high proportion of attestation service means that if a blockchain audit has mature applications in the future, the impact on accounting firms will be very huge.

In terms of technical tools, relying on strong economic strength and huge business needs, the international "Big Four" have built their own R\&D center with heavy investment, gathering IT talents, business elites and specialized research talents to carry out the research and

\section{A. Improving Information Investment}

Insufficient investment in information technology is a common phenomenon among Chinese firms. To enhance the competitiveness of the firm, Chinese domestic-fund firms must strengthen information construction. Today, big data is widely used. The "Big Four" accounting firms have gradually introduced intelligent robots to replace manual labor. In July 2017, China's Ministry of Finance issued the "Certified Public Accountants' Informationization Promotion Work Plan", and the informationization construction has been put at the strategic height of the development of accounting firms. On the one hand, information construction can realize internal information circulation, reduce costs and improve efficiency. On the other hand, it can adapt to the needs of audit services in the new Internet era and better control audit risks. Especially for the R\&D and application of blockchain in the field of audit, Chinese domestic-fund firms should take corresponding measures to follow up in time and participate in the research of blockchain. For example, Chinese domestic-funded firms can choose to collaborate with universities to create blockchain laboratories, or invest in blockchain start-ups, or set up their own blockchain teams to develop their own position in the new sector of blockchain audit.

\section{B. Improving the Professional Competence of Auditors}

Knowledge is the most valuable core resource of the enterprise, and talent is the value carrier of knowledge. To improve the competitiveness of accounting firms, it is necessary to create a high-quality talent team. The combination of future blockchains and artificial intelligence may largely replace the current cumbersome basic financial work. Low-level accountants and auditors will not be needed, and those high-end financial personnel with management knowledge and strong analytical decision-making capabilities can't be replaced. The firm should cultivate more high-end accounting talents and organize regular training to encourage employees to learn professional knowledge. At present, China's blockchain technical talents are extremely scarce, and there are very few compound talents who understand blockchain knowledge and financial knowledge. Therefore, the firm should develop a compound financial officer who has research on the blockchain and conduct training on the blockchain technology for auditors. 
[13] Chen Xu, Ji Chenghao. Real-time audit research based on blockchain technology [J]. Chinese Certified Public Accountant, 2017(04): 67-71. (in Chinese)

[14] Zhang Liucheng, Yu Linlin. The Impact of Blockchain Technology on Audit [J]. China Agricultural Accounting, 2018(01): 24-26. (in Chinese)

[15] Li Yishuo. Blockchain: leading to subversive changes in the accounting industry [N]. China Accounting, 2016-7-29. (in Chinese)

[16] Li Zhiguo. Research on the application of financial system based on blockchain [D]. China University of Geosciences (Beijing), 2018. (in Chinese)

\section{REFERENCES}

[1] Swan M. Blockchain: Blueprint for a New Economy. USA: O0Reilly Media Inc., 2015.

[2] Su Lina, Li Jiaqi. How do governments view the blockchain? [J]. Cards World, 2016 (10): 23-24. (in Chinese)

[3] Nakamoto S. Bitcoin: A peer-to-peer electronic cash system [J]. 2008.

[4] Pan Haoqiang, Chen Junlan. Research on the application of blockchain in the field of audit [J]. Accounting Learning, 2018 (18): 142-143. (in Chinese)

[5] Yuan Yong, Wang Feiyue. Blockchain: The State of the Art and Future Trends [J]. Acta Automatica Sinica, 2016, 42(04):481-494. (in Chinese)

[6] Wang Xinqing. On the Principles of Technological Innovation of Blockchain and Its Application in Financial Industry [J]. Journal of Henan College of Financial Management Cadres, 2019, 37 (02): 8-13. (in Chinese)

[7] Nie Yushan, Zhang Li. On the Influence and Prospect of Blockchain Accounting Development [J]. Financial Supervision, 2018 (23): 8994. (in Chinese)

[8] Chen Yixi. Research on the "Impossible Trinity" of Block Chain technology and the problems should pay attention to [J]. Zhejiang Finance, 2016(02):17-20+66. (in Chinese)

[9] Si Shuxian. Reshaping the Accounting Industry in the Age of Big Data-Based on the Analysis of Blockchain Perspective [J]. Research of Financial \& Accounting, 2017(09):24-28. (in Chinese)

[10] Zhai Sheping, Li Zhaozhao, Duan Hongyu, Gao Shan. Research on Data Consistency of Key Technologies of Blockchain [J]. Computer Technology and Development, 2018, 28(09): 94-100. (in Chinese)

[11] Li Zhengdao, Ren Xiaocong. The Impact of Block Chain on the Internet Finance and its Future Prospects [J]. Technoeconomics \& Management Research, 2016(10): 75-78. (in Chinese)

[12] Liu Muxuan. Principle and application value of blockchain technology $[\mathrm{J}]$. Electronic Technology and Software Engineering, 2018 (22): 7. (in Chinese) 